in the archives clearly demonstrate the Ottoman concern for the conservation of the forests. ${ }^{1}$ The author furthermore deals with the foreign experts in the Spanish shipyards and focuses on the importance of Genoese craftsmen, carpenters and caulkers in the arsenal of Barcelona (p. 168).

Gugliuzzo's work is very ambitious as she aims to cover all major naval construction centers in the Mediterranean except the Venetian arsenal. This book deals with the Ottoman naval policy, Tersâne-i Âmire, the Knights of Malta, the arsenal of Birgu, the shipyards of Messina and lastly the Spanish maritime policy and the royal arsenal in Barcelona. This should be a challenging task to achieve in only 249 pages. For that reason, this book inevitably lacks the necessary details and references. The introduction of the book focuses on the Military Revolution which has no or very little relevance to the title of early modern seaports. Although every chapter has its own plan and conclusion, the book does not include a general conclusion which evaluates the study. Furthermore, it does not establish a relation among the major naval centers in the general context of the Mediterranean history.

\author{
Hüseyin Serdar Tabakoğlu \\ Kırklareli University
}

Palmira Brummett,

\title{
Mapping the Ottomans: Sovereignty, Territory, and Identity in the Early Modern Mediterranean,
}

New York: Cambridge University Press, 2015, xviii +365 pages, $113 \mathrm{~b} / \mathrm{w}$ illus., 15 colour plates, ISBN: 978-110-7090-77-4.

This book is about more than merely maps. The "mapping" in the title encompasses more than making drawings of coastlines, rivers, mountains, and cities on flat sheets of paper. Beyond delineating, mapping is also an activity of appropriating, compartmentalizing, characterizing, representing, and misrepresenting.

I İdris Bostan, Osmanlı Bahriye Teşkilatı: XVII. Yüzyılda Tersane-i Amire (Ankara: Türk Tarih Kurumu, I992), IO2-I2O. 
This is particularly true of the representation of the European ideas of the Ottoman Turks - the "Other" - in the $16^{\text {th }}, 17^{\text {th }}$, and $18^{\text {th }}$ centuries. The ways in which these commercial, diplomatic, military, and personal perceptions were recorded by Europeans in their maps and travel narratives are closely scrutinized in this well-written and richly-illustrated study of Early Modern cartography, iconography, and rhetoric. One-hundred and twenty-eight maps are reproduced and examined. The symbolic images used on the maps are disclosed. The messages encoded in the images are identified. How the images are manipulated to convey the messages is revealed. The purpose of the book is to uncover, identify, and interpret how the Ottoman Turks were envisioned and imagined by Europeans in both image and text, primarily through an examination of the maps representing the lands and seas of the Ottoman Empire, and the associated texts and narratives. The thesis is that the maps, images, and narratives by Europeans are mediated through a discourse of signs and symbols which can be deconstructed and "read" to reveal the underlying assumptions Europeans held about themselves and the Ottomans and the space between them. The author argues her case by a deep and detailed analysis of the words and pictures, narratives and maps, made by Europeans of the Ottoman Turks and their lands, but also in Ottoman self-mapping. During this period, the Ottoman Empire stretched from Algiers to the Caspian Sea, from the Horn of Africa to the Gates of Vienna, but the focus of the book is chiefly upon the borderlands of Eastern Europe and the Eastern Mediterranean between the two empires of the Hapsburgs and the Ottomans.

The work is not strictly about cartography and may more appropriately be thought of as "visual rhetoric," that is, an analysis of the discourse by which images are used to create meaning, often in collaboration with a written text, to persuade an audience of an argument or position, or legitimatize an existing power structure, or sanctify shared community values. On the face of most (if not all) maps are vignettes, portraits, icons, names, words, phrases, sentences, and text. Much of the discussion and analysis is explaining how the images and associated texts amplify and clarify, expound and drive home, the hidden agenda and veiled message of the map. Often text in the form of narratives, diplomatic reports, campaign accounts, merchant itineraries, captives' testimonies, travel journals, and pilgrimage tales is accompanied by maps illustrating the routes of journeys and locations of events. Itineraries from narratives of eyewitnesses who had actually travelled through the permeable, transimperial boundaries to the "exotic" East, were highlighted on the face of maps to lend authority and legitimacy, through 
seeming privileged knowledge, to the depiction of the interpreted space encompassed by the map. Narratives often recount of places as seen by the eye of an educated witness through the prism of the past. Constantinople, the center of Ottoman power, was at the same time also the former seat of the Eastern Emperors. Jerusalem was always to be the Holy City and its Jewish and Christian importance always noted on the map, even though it was in Ottoman territory. The lands of the Middle East were spoken of as eventually being returned to Western hegemony but, tellingly, Europeans never articulated their own space, their lands, their Europe, as an eventual tableau of Ottoman conquest. The eye can see everywhere but into itself, and the European mapmakers were oblivious to their own biases and predispositions.

Since the beginnings two-hundred years ago of the history of cartography as an field of scholarship, it has been overshadowed by two assumptions about the history of maps and mapmaking: 1) it is the pictorial recording of the advancing expansion of geographical knowledge, especially by Europeans; and 2) it is the history of the continually increasing improvement in the accuracy of maps, moving away from the "quaint" distortions of the more "primitive" maps of the past and, by the impersonal gathering of impartial facts, progressively becoming an objective form of knowledge grounded in science. In the last thirty years, the theoretical foundations of the history of cartography have taken steps away from this domination by the history of geography and the narrow claims of the makers of maps. The non-geographical, that is, the decorative and textual, elements of European-made maps were previously viewed as old-fashioned and superfluous. Professor Brummett has fixed upon these non-geographical elements of cartography to expose the social and human aspects portrayed in the maps, and the social and human aspects that drive the creation of the maps, that are reflected in the symbols and semiotics of the map, that are encoded by the mapmaker with the language of images and signs understood by the audience of the map. Today, maps are viewed as representations of institutional power, governmental control, and the social order. Professor Brummett's presentation reveals maps to be canvases of space - tabulae rasae - on which the mapmaker, as a voice representative of his time and place and culture, renders the shared vision of that space. These spaces are sometimes war space, sometimes commercial space, sometimes spaces of shared ethnicities and nationalities. Sometimes the space is presented as disputed space, sometimes divided with hard borders where no such firmness existed, only the prejudicial perception of the mapmaker and his milieu. But it is always space 
as envisioned by European culture and articulated through the map. The maps were routinely used to delineate the contested territory, the frontier zone between Europeans and Ottomans, thus futilely attempting to pinpoint and delimit a vague, fluctuating space as the possession of European Christendom. And, if not the property at present, then soon to be in the on-again, off-again, wars. The hard, immutable lines of printed ink on the authoritative map created the illusion of a place of unquestionable extent and location, banished any hint of ambiguity, and forever immobilized and made concrete the disputed target. The triumph over space and territory was frequently emblemed with images of fortresses, armies, captives, corpses, and severed heads.

An important theme repeatedly returned to by the author is the layering of historical time in the maps and narratives. Events of the past were exhibited on the terrain of the present. Over and over, again and again, cities and provinces in the Ottoman lands are reidentified and labeled with their Classical or Biblical names, and the events of the distant past are juxtapositioned with contemporary times. Quoting ancient authors on the face of a map tied the present-day locations to their past, non-Turkish, histories, and lent authority to the European interpretation of the visualized space. A single map frequently entwined and interwove the spaces of the past, present, and future, with political space, journey space, and conflict space. The presence or absence of ships (friend or foe) in the surrounding seas, or scenes of marching armies on the nearby shores, or the sizes and details of fortresses, can give to the map reader a sense of confidence and security, or a foreboding of the dangers and risks of contested lands and islands. Maps could be drawn from a peculiar perspective, such as a bird's-eye-view, to frame the map reader's perception and assessment. Distances could be collapsed or expanded to fit the requirements of the contention being asserted, which was predominately presented in an unconscious argument, formed by the social structures of the mapmaker, and formulated in a common symbolic language to authorize and authenticate the world view of those social structures, e.g., monarchies, bureaucracies, religious organizations, class hierarchies, social rankings, etc. The lines drawn for edges of shores and courses of rivers fade into the background of the map and become secondary to the so-called "decorative" elements of the map. These decorative elements, such as, scenes of people, their dress, buildings, flags, coats-of-arms, scenes, events, horses, weapons, ships, etc., are brought to the forefront against the geography of lines to explicate the message of the map. 
Though it would be expected that the Ottoman Turk would, in the European imagination, be perceived as both foreign and enemy, the ubiquitous images of the "Turk" in European maps and narratives betray a greater variety of motifs and topoi. Europe vs. Asia, Christianity vs. Islam, the West vs. the Orient, Sacred vs. Profane, and other basic dualisms were consciously used by Europeans. But the evidence of the documents, the maps and associated narratives, which together form the focus of Professor Brummett's study, present a much greater variety, complex, and nuanced imagery than can be subsumed under the simplistic dichotomies. The depictions and meanings of fortresses depicted on maps, for instance, receive special attention. As formulaic icons, they were used on maps to represent dominion and power and control over the surrounding territory. If an area or territory had changed hands from Christian to Muslim, or even if never in the power and control of the Europeans, on the map it could still be shown as "belonging" to the West; a flag with a cross placed here or portrait of a sovereign there, was all that was needed to show the subjugation of vast swaths of the frontier lands of the Greco-Balkan Peninsula, between Venice and Vienna on one flank and Constantinople on the other.

To read this book is to train one's eye to look beyond the merely geographical or ornamental on a map and, instead, expand one's vision to decode the semiotics and rhetoric of the imagery and text, to learn to read what the mapmaker is consciously and unconsciously saying with his map and how he uses the language of cartography to convey that statement. The exposure and articulation of the authentic nature of maps as fundamentally representations of power, sovereignty, territory, and identity - this is the essential point of Brummett's work. It emerges that the seemingly incidental aspects of the map unmask and subvert the outward public meaning of the map. Geographical accuracy is subordinated to the political and cultural message of the map. And the message was clearly the preeminence of Christian Europe over the Muslim Ottoman Turks, and the legitimacy and authority of the European power structures, i.e., the political, social, and religious institutions, in imposing that supremacy, even if only on paper.

\section{Gregory C. McIntosh \\ Piri Reis University}

